\title{
Dilemmas of Rawlsian Opportunity
}

\author{
PAUL GOMBERG \\ Department of History, Philosophy and Political Science \\ Chicago State University \\ Chicago 60628 \\ USA \\ pgomberg@csu.edu
}

In A Theory of Justice and elsewhere John Rawls writes that the basic structure of any society affects the life prospects of those growing up in different 'starting places,' yet his conception of equal opportunity seems to require that one's opportunities not be affected by the class position of one's birth. ${ }^{1}$ Here I explicate this apparent contradiction and reconcile these assertions. In Rawlsian fair equality of opportunity children from working-class families have lesser opportunity to attain advantaged positions.

Rawls's view cannot be easily revised to allow equal prospects for all children. Within the framework of Rawls's understanding of a just society, he is right to say that his own conception of fair equality of opportunity allows deep inequalities in life prospects.

Nevertheless, Rawls's vision of a just society rests on some dubious sociology. Moreover, Rawls's assumed division of labor - between highly trained and less skilled labor - unjustly blunts the development

1 The primary texts cited will be A Theory of Justice revised edition (Cambridge: Harvard University Press 1999), hereafter cited as Theory with page numbers in text, and Justice as Fairness: A Restatement, Erin Kelly, ed. (Cambridge: Harvard University Press 2001), usually cited as Restatement with page numbers in text. 
of ability in many children. Equal opportunity for all children regardless of class of origin would require abolition of that division of labor.

\section{Rawlsian Fair Equality of Opportunity and the Basic Structure}

Rawls's conception of equal opportunity seems to imply abolishing advantages associated with class position. In his late Justice as Fairness: A Restatement he writes

...fair equality of opportunity is said to require not merely that public offices and social positions be open in the formal sense, but that all should have a fair chance to attain them. To specify the idea of fair chance we say: supposing that there is a distribution of native endowments, those who have the same level of talent and ability and the same willingness to use these gifts should have the same prospects of success regardless of their social class of origin, the class into which they are born and develop until the age of reason. In all parts of society there are to be roughly the same prospects of culture and achievement for those similarly motivated and endowed. (43-4)

In $\$ 12$ of Theory he criticizes not only 'the system of natural liberty' but also the 'liberal conception' of the second principle of justice. (The liberal conception would advance fair equality of opportunity but would distribute wealth and income according to market rewards for ability.) He writes that the principle of fair opportunity can only be imperfectly carried out' in the liberal conception. The development of natural ability 'is affected by all kinds of social conditions and class attitudes.' As a result, 'it is impossible in practice to secure equal chances of achievement and culture for those similarly endowed' (Theory, 64). These inequalities, apparently, would be not be present on the democratic conception, where distribution would be based on the difference principle. $^{2}$

Rawls defends two principles of justice as ordering relations among people in a system of social cooperation. The first is 'a fully adequate scheme of equal basic liberties, which scheme is compatible with the same scheme of liberties for all.' The second principle of justice allows social and economic inequalities provided that those inequalities meet two conditions: there must be fair equality of opportunity to attain the more advantaged positions and inequalities must benefit the least

2 I argue shortly that this is a misinterpretation, and that Rawls does not believe that these inequalities disappear on the democratic conception of justice, but that they achieve a specific social purpose on that conception. 
advantaged members of society, the second condition being called 'the difference principle' (for the principles of justice see Restatement, 42-3; cf. Theory, 266-7).

When, in Theory, Rawls introduces the principle of fair equality of opportunity, he explains it in words similar to those in Restatement, as follows: 'assuming that there is a distribution of natural assets, those who are at the same level of talent and ability, and have the same willingness to use them, should have the same prospects of success regardless of their initial place in the social system. In all sectors of society there should be roughly equal prospects of culture and achievement for everyone similarly motivated and endowed. The expectations of those with the same abilities and aspirations should not be affected by their social class' (\$12 at 63). Superficially this seems to mean that in any society where there is fair equality of opportunity, social class of origin will simply make no difference to a child's life prospects.

Yet there are passages where Rawls writes that class of origin affects life prospects. In Theory he explains the basic structure of a society as follows:

...this structure contains various social positions and...men born into different positions have different expectations of life determined, in part, by the political system as well as by economic and social circumstances. In this way the institutions of society favor certain starting places over others. These are especially deep inequalities. Not only are they pervasive, but they affect men's initial chances in life.... It is these inequalities, presumably inevitable in the basic structure of any society, to which the principles of social justice must in the first instance apply. (7)

'Deep inequalities...affect[ing] men's initial chances in life' are inevitably part of any society.

In Restatement Rawls reiterates that the class position of the family in which we grow up affects our life prospects. Here he explains the basic structure as follows:

Justice as fairness focuses on inequalities in citizens' life-prospects - their prospects over a complete life... - as these prospects are affected by three contingencies:

(a) their social class of origin: the class into which they are born and develop before the age of reason;

(b) their native endowments...; and their opportunities to develop these endowments as affected by their social class of origin;

(c) their good or ill fortune, or good or bad luck... (...illness and accident...involuntary unemployment...).

Even in a well-ordered society, then, our prospects over life are deeply affected by social, natural, and fortuitous contingencies, and by the way the basic structure, by setting up inequalities, uses those contingencies to meet certain social purposes. 
Within a few pages Rawls writes that there is some tendency for individuals most adversely affected by the three contingencies...to be among the least advantaged' (65). Hence with 'fair equality of opportunity' social class of origin can adversely affect our life prospects, especially opportunities to develop our 'endowments.' In Restatement he writes, 'when [the difference principle] is met, those with lesser opportunity can accept more easily the constraints the family and other social conditions impose' (163, emphasis added; cf. Theory 448 and note 6 below). For Rawls the basic structure, even a just one, creates unequal life prospects for children growing up in different social classes.

How is 'lesser opportunity' for children growing up in a less advantaged class compatible with 'fair equality of opportunity?' Explicating the difference principle in a 1967 paper, 'Distributive Justice,' Rawls writes

the inheritance of greater wealth is just as long as it is to the advantage of the worst off and consistent with liberty, including equality of opportunity. Now by the latter we do not mean, of course, the equality of expectations between classes, since differences in life-prospects arising from the basic structure are inevitable, and it is precisely the aim of the second principle to say when these differences are just. Instead, equality of opportunity is a set of institutions which assures equally good education and chances of culture for all and which keeps open the competition for positions on the basis of qualities reasonably related to performance, and so on. It is these institutions which are put in jeopardy when inequalities and concentrations of wealth reach a certain limit. ${ }^{3}$

Here Rawls gives an interpretation of equal opportunity that makes it consistent with his statement that 'differences in life-prospects aris-

3 John Rawls, Collected Papers, Samuel Freeman, ed. (Cambridge: Harvard University Press 1999), 130-53 at 143. A similar passage is in Theory §43, 245-6. In Theory the phrase 'equally good education and chances of culture for all' is replaced by 'similar chances of education and culture for persons similarly motivated.' The insertion of the proviso about motivation is quite important, as we will see shortly. In Theory the thought contained in the sentence 'Now by the latter we do not mean, of course, the equality of expectations between classes, since differences in lifeprospects arising from the basic structure are inevitable...' is omitted. Why did he omit this sentence in Theory? The interpretation offered here is that he did not change his mind. Still, the juxtaposition of these two thoughts probably bothered him. I believe that he did not work through, as I will do here, the reconciliation of his ideas about equal opportunity with his ideas about the basic structure creating differences in life expectations. He may have been uncomfortable with juxtaposing the thoughts that the basic structure creates unequal life prospects and that justice requires that social class not affect the life prospects of those similarly endowed and motivated. 
ing from the basic structure are inevitable.' This passage fleshes out the meaning of Rawls's assertion in Restatement that 'the basic structure, by setting up inequalities, uses those contingencies to meet certain social purposes' (55, emphasis added). For Rawls social class of origin may entail differences in life prospects as long as those inequalities advance the prospects - including opportunities - of the least advantaged.

In Theory he writes that in order to justify unequal opportunity one must 'claim that the attempt to eliminate these inequalities [of opportunity] would so interfere with the social system and the operations of the economy that in the long run anyway the opportunities of the disadvantaged would be even more limited. The priority of fair opportunity...means that we must appeal to the chances given to those with the lesser opportunity. We must hold that a wider range of more desirable alternatives is open to them than otherwise would be the case' (265). He summarizes, 'an inequality of opportunity must enhance the opportunities of those with the lesser opportunity' (266). So this must be true of the differences in life prospects entailed by the basic structure.

Still, Rawls's writings seem inconsistent. How can he reconcile children having 'the same prospects for culture and achievement' with some having their life prospects adversely affected by social class of origin? And what about the passage in $\$ 46$ of Theory where Rawls writes that the second principle 'requires equal life prospects in all sectors of society' (265) and passages cited earlier saying the same? The answer is that whenever Rawls writes about equality of life prospects as required by fair equality of opportunity, he writes that it 'requires equal life prospects in all sectors of society for those similarly endowed and motivated' (265 emphasis added; see the 'Distributive Justice' passage above for the exception and note 3 for discussion). Suppose that Rawls believes that class of origin inevitably tends to affect motivation. Then his belief that we should have equal life prospects in all sectors for those equally endowed and motivated would be consistent with his belief that class differences inevitably affect initial chances in life.

When Rawls explains the difference principle he writes of 'social contingencies' that favor some over others just as 'native endowments' do. He writes, 'That we deserve the superior character that enables us to make the effort to cultivate our abilities is also problematic; for such character depends in good part upon fortunate family and social circumstances in early life for which we can claim no credit' (Theory, 89). If 'social circumstances' include class, then he may believe that class of origin affects motivation.

To understand this better, let us return to the $\$ 12$ passage in Theory briefly discussed earlier; there he criticizes the liberal conception of the second principle of justice. This passage shows that he believes there is a connection between a person's class of origin and motivation. Let us 
take a more detailed look at these words, but with emphasis added. In the liberal conception of the second principle of justice

\begin{abstract}
the principle of fair opportunity can be only imperfectly carried out, at least as long as some form of family exists. The extent to which natural capacities develop and reach fruition is affected by all kinds of social conditions and class attitudes. Even the willingness to make an effort, to try, and so to be deserving in the ordinary sense is itself dependent upon happy family and social circumstances. It is impossible in practice to secure equal chances of achievement and culture for those similarly endowed, and therefore we may want to adopt a principle that recognizes this fact and also mitigates the arbitrary effects of the natural lottery itself. That the liberal conception fails to do this encourages one to look for another interpretation of the two principles of justice. (64)
\end{abstract}

What leads us to look for another interpretation? One might think that the reason is that the liberal conception fails to create equal opportunity for children growing up in different classes. But the passage does not say that this is why we need another interpretation. The liberal conception is unsatisfactory because it fails to recognize a fact and to mitigate the effects of the natural lottery. The alleged 'fact' is that it is impossible to secure equal chances of achievement and culture for those similarly endowed (not those similarly motivated). Why is this impossible? The explanation seems to be that social conditions and class attitudes affect motivation and hence the realization of one's 'native endowment.' This is true for two reasons. One, stressed in $\S 77$ of Theory, is that families in the same social sector may advantage their children unequally. The second, suggested here in $\S 12$, is that the class position of families affects motivation and hence opportunity to develop 'endowments' (see also Restatement 55, subparagraph (b) quoted earlier).

Now we can understand why Rawls writes in Theory that 'the institutions of society favor some starting places over others,' creating 'deep' and 'pervasive' inequalities that 'affect men's initial chances in life' (7). Rawls believes that one's 'starting place' affects the motivation one is likely to develop to exercise one's 'native endowments.' On this view fair equality of opportunity for all people who are 'similarly endowed and motivated' does not imply equal life prospects for children growing up in more advantaged and less advantaged families.

The phrase 'recognize this fact' in $\S 12$ of Theory implies that a different conception of justice will not alter the fact. In a society governed by Rawls's democratic conception of justice the natural and social lotteries still create inequalities; class attitudes and social conditions still affect willingness to make an effort. The justification of inequality is different; the democratic conception requires that inequalities in life prospects, unequal opportunity, be used to advance the prospects, including the opportunity, of those least advantaged. These are the 'certain social 
purposes' that the basic structure meets by 'setting up inequalities' (Restatement 55). ${ }^{4}$

To recapitulate: Class background affects motivation to develop talents; children from advantaged families are more motivated and hence have a class-based advantage in the competition to determine who holds the more advantaged positions. ${ }^{5}$ Advantage tends to be somewhat selfperpetuating. For Rawls this advantage is just when the advantages of the social lottery of class of origin as well as those of the natural lottery of talents benefit those less advantaged. ${ }^{6}$

Rawls believed that opportunity for children from different class positions is unequal because children from lower class positions are less motivated to develop their abilities. But why would 'a wider range of desirable alternatives [be] open to [those with lesser opportunity] than would otherwise be the case' (Theory 265)?

Rawls seems to assume that where people have more material goods, they have more opportunity. He writes that 'those who start out as members of the entrepreneurial class in property-owning democracy, say, have a better prospect than those who begin in the class of unskilled

4 Why does Rawls object to the liberal conception that 'the principle of fair opportunity can only be imperfectly carried out'? On both interpretations inequalities in life prospects arise from one's class position. But for Rawls, fair opportunity requires that inequalities in opportunity advance the opportunities of those with least opportunity. The liberal conception does not guarantee that, and that is why, on the liberal conception, the principle of fair equality of opportunity cannot be perfectly carried out.

5 Did Rawls also believe that class position affected one's 'native endowments'? This much is clear. He thought that in a just society those who held positions of advantage tended to be those who had greater scarce 'native endowments'; the passage at Restatement 65 quoted above implies that he thought that those 'least endowed' were disproportionately represented among the least advantaged. Did he believe that people inherited greater and lesser 'endowments' from their parents? The eugenic passage at Theory 92 suggests that he thought something like this; at 245 he speaks of the 'unequal inheritance of intelligence' as though it were an established fact. Although his use of the phrase 'natural lottery' may be thought to suggest that 'endowments' are random, the randomness he intends is 'morally random' or undeserved rather than 'naturally random.' Still, even if present, the belief that 'endowments' are affected by class position is a very secondary theme in Rawls.

6 In Theory $\$ 77$ at 448 , considering how family circumstances affect life chances for different individuals, Rawls writes that those of us who are disadvantaged by natural and social contingencies 'are more ready to dwell on our good fortune now that these differences [in natural and social advantages] are made to work to our advantage, rather than be downcast by how much better off we might have been had we had an equal chance along with others if only all social barriers had been removed.' 
laborers.' He writes that this 'initial inequality in life prospects' is 'justifiable only if the difference in expectation is to the advantage of the representative man who is worse off, in this case the representative unskilled worker.' The advantage of the entrepreneur (and of those born into the entrepreneurial class) must 'raise the prospects of laboring class [sic]' and make 'the economic process...more efficient, innovation proceed[ing] at a faster pace, and so on' (Theory $67-8)^{7}$. Does this improve the worker's opportunity? Rawls has argued that more goods will be produced (and presumably distributed to the worker). If opportunity is opportunity to obtain more goods, then the worker has greater opportunity.

Identifying opportunity with having more things is problematic for two reasons. First, consider positional goods, those that affect our standing relative to others. ${ }^{8}$ Can more things for those least advantaged raise them positionally? No, because having more things elevates their relative position only if it raises them above others, and, by definition, more things for the least advantaged does not do this. Second, it is plausible to suppose that development and contribution of complex abilities to a social group is an important part of a good life. Unequal opportunity deprives them of this: instead they labor for the entrepreneur. ${ }^{9}$

7 This passage could be interpreted as being about unequal expectations among adults rather than about the prospects of children born into different classes. Still, the language here of a person's 'prospects' is the same language he uses when writing about opportunity, and the phrases 'start out' and 'initial inequality in life prospects' suggest he is thinking about opportunity. In any event, this is the closest he comes to explaining why unequal opportunity might be thought to increase the opportunity of those with lesser opportunity, and I believe his explanation of why this is so - more material resources to the less advantaged - has to be the same in both the case of opportunity and the more general case of the expectations of the representative person of different classes.

8 On positional goods see Fred Hirsch, Social Limits to Growth (Cambridge, MA: Harvard University Press 1976). To the extent that important goods are positional, what is important is relative position (ranking), not how well off one is in a more objective sense. On the problems that positionality makes for prioritarian conceptions of justice see Harry Brighouse and Adam Swift, 'Equality, Priority, and Positional Goods,' Ethics 113 (2006) 471-97.

9 The interpretation developed here of how Rawls imagines the social division of labor - between, on the one hand, those who organize and design the productive process or who do highly trained technical or intellectual labor and, on the other, those who labor in production doing simpler, less skilled labor - leans heavily on this example of how the difference principle is to be understood. This may be unfair to Rawls, but I am not sure. There are other elements in Rawls's egalitarianism that emphasize the wide dispersal of property, including the 'powers of office' attaching to ownership and workplace democracy; these elements suggest a much 
Having more things does not address this good. Instead we may use possession of things to try to compensate for joyless work.

To develop this second point: in the United States - and surely elsewhere - many children's potential is not well developed; moreover, children cannot have confidence that, as adults, they will have the opportunity to contribute abilities they develop, as a physician, musician, architect, or philosopher. Opportunities to contribute developed complex abilities are scarce. As a result, many children, in the United States especially disadvantaged black children, anticipate at best a life of routine labor. In Rawls's words, they are 'debarred from experiencing the realization of self that comes from a skillful and devoted exercise of social duties' (Theory 73). Rawls makes this observation in explaining why positions must be open to talents. But Rawls's conception of fair equality of opportunity seems open to a similar objection: social class of origin affects a child's prospects of being able to achieve self-realization by performing social duties requiring great skill; many have little chance of attaining this important good. These considerations give us reason to seek a conception of equal opportunity where class position does not affect the likelihood of being able to develop and contribute our abilities.

\section{Why Rawls Rejects Truly Equal Opportunity}

Let us define truly equal opportunity as opportunity where a child's life prospects are unaffected by class of origin. Could limits on inequality implied by the difference principle combine with aggressive policies insuring educational equality to create equal prospects for children from all economic, social, and cultural backgrounds? Here I argue that, given his understanding of a just society, Rawls rightly rejects equal prospects.

\section{Class position and motivation}

Rawls believed that children from less advantaged families had lesser life prospects because they were likely to be less motivated to develop their abilities. But why should this be true? Perhaps children from advan-

more egalitarian view that is not so focused on distributive benefits of the division of labor. But, to my mind, they also threaten to void any application of the difference principle and make puzzling his belief that 'profound inequalities' are inevitable. I explore the apparent duality of Rawls's egalitarianism briefly in the appendix. 
taged families are surrounded by examples that effort is rewarded by success while less advantaged children do not see as much reward for effort. If class of origin did not affect life prospects, then neither would it affect confidence and motivation to develop abilities. This reason for differences in motivation would be unacceptable to Rawls because here the ultimate reason for differences in motivation is differences in life prospects, apart from motivation.

There is another, less objectionable, reason to agree with Rawls that class of origin will affect children's motivation to develop their abilities. Children are likely to find their parents particularly compelling role models. If some grow up in families of manual workers and others in families of intellectuals, are we to suppose that these models make no difference in whether the children are likely to succeed in competition for limited positions? A system of compensatory education might try to provide role models from outside the family, but these models might not be as compelling. Consider, for example, how affective ties to one's parents might influence one's sense of appropriate training and occupation.

The 'role model' argument endorses Rawls's belief that family of origin influences motivation. It does so on the assumption of competition for limited positions of advantage. This assumption is implied in Raw$1 s$ 's belief that efficiency requires inequality. Hence Rawls's vision of a just society is one where economic incentives are offered to recruit people with scarce native abilities to a few positions demanding exercise of highly developed skills (thus requiring them to educate their native abilities in order to develop those skills), but only enough incentive to benefit all, including the least advantaged. On this assumption about how labor is organized a small difference, a more compelling role model, may make the difference between success and failure. Some competitors for limited opportunity must become discouraged in the competition; if this did not happen, all losing competitors would continue to hold out hope that their aspirations would be realized, but when many people have frustrated ambitions, their frustration contributes to social instability. ${ }^{10}$ Societies with limited and hence competitive opportunity have social mechanisms that discourage competitors and adjust aspirations to the quantity of opportunity. ${ }^{11}$ Differences in the compellingness

10 See Seymour Martin Lipset and Richard Bendix, Social Mobility in Industrial Society (Berkeley: University of California Press 1959), 262.

11 There is a paradox here: limited opportunities are competitive because the number with high aspirations exceeds the number of available advantaged positions. But social stability requires that aspirations be adjusted to the available opportunities. But this adjustment reduces competition. Hence stability requires the reduction of competition. 
of role models are part of a process whereby some become discouraged. In the absence of other deciding factors, role models may be decisive in adjusting aspirations.

\section{Equal opportunity and the liberty principle}

Could compensatory education cancel class advantages with 'equally good education and chances of culture' for all children? We should not underestimate the difficulty. The difference principle alters the basis on which inequalities are justified; in principle, the same problem arises for the democratic conception as arose for the liberal conception: economic and cultural inequalities create unequal opportunity. Parents use their resources to convey cultural mastery to their children, through enriching experiences (taking trips to volcanic parks or to museums and cathedrals) or by taking time from work to spend with their children; doing this is easier for those with more money. When one parent has a high income the other may become a full-time tutor, teaching the children to read at an early age, teaching them arithmetic and mathematics, exposing them to music and scientific culture. Given the time spent and affective ties between parents and their children, compensatory education is unlikely to match these advantages and to create 'equally good education and chances of culture' for all children.

The arguments I have given could be defeated if parents with greater income and wealth could be prohibited from using that wealth to advantage their children; accordingly, we might imagine a prohibition on private schools, paid tutorial services, or monetary aid to children past a certain age. Could we also prohibit using greater economic resources to fill the home with educational materials? These proposals seem to violate liberty; that is, such interference with how one may spend one's money seems so great an interference with liberty that it would deprive one of a 'fully adequate scheme of equal basic liberties.' Certainly this would seem to be so if the state were to prohibit parents from working less in order to spend more time educating their children.

I conclude that compensatory education for children of the less advantaged would likely be insufficient to cancel income and wealth advantages unless we prohibited parents from bringing educational materials inside the home, using their resources to give their children enriched experiences, prolonging their educational opportunity, or even spending more time with them. These prohibitions would violate the liberty principle. 


\section{Equal opportunity and the difference principle}

Truly equal opportunity seems incompatible with the difference principle. Either those with greater income and wealth can convey advantages to their children or they cannot. Suppose they can (as I have argued). Then truly equal opportunity requires wealth equality; it voids application of the difference principle.

Now suppose that those with greater income cannot convey advantages to their children perhaps because (contrary to the argument of the last subsection) a public system of 'affirmative action' cancels the effect of any significant income and wealth inequalities. But why should one seek greater income and wealth? One central motivation as parents is to make the life prospects of our children as good as possible. Truly equal opportunity makes it impossible to give some children an edge over other children in the competition for advantage. This could be demoralizing to parents. For many, advantaging their children is central to their conception of the good. ${ }^{12}$ Disallowing the use of extra income to advantage their children would make some people unwilling to train and contribute their abilities (assuming, with Rawls, that an extra incentive is needed for this). If social institutions make it impossible for parents to advantage their children, then it is not obvious how effective the 'differences' enjoined by the difference principle will be in creating incentives. So truly equal opportunity could undermine the difference principle by defeating the incentives it enjoins.

Truly equal opportunity (life prospects unaffected by class of origin) seems incompatible with the liberty and difference principles. If significant income and wealth differences, even ones narrower than at present, can be translated into advantages to children, then truly equal opportunity would require us to limit liberty. Or, if people cannot advantage their children in the competition for advantage, truly equal opportunity seems incompatible with the difference principle. There are two problems. The difference principle allows inequalities as incentives to induce people to develop and contribute abilities in a way that creates distributive benefits for the least advantaged. Truly equal opportunity threatens both the inequalities and the incentives. Hence, given his understanding of a just society, Rawls is right to reject truly equal opportunity.

12 In The Failures of Integration: How Race and Class are Undermining the American Dream (New York: Public Affairs 2004), Sheryll Cashin argues that many parents spend great sums to live in neighborhoods whose schools advantage their children. 


\section{The Difference Principle and Rawls's Dubious Sociology}

However, that is not the end of the matter. Is it an injustice that, as the argument of the previous section implied, some children are socialized so as to limit competition for limited positions of advantage? It is not unjust if this socialization is just a process of people realizing that their native endowments do not suit them for highly complex labor. Then, as Rawls says, deep inequalities are inevitable. But is he right about this?

\section{Sociological assumptions}

Let me draw together two threads from the last section. A plausible reason (acceptable to Rawls's argument) why class of origin might affect motivation is that, given affective ties, parents are a particularly compelling role model for children in developing their abilities and that, given the division of labor between very complex labor and routine relatively unskilled labor, children are likely to be differently motivated to develop more complex intellectual abilities. Since opportunity is limited, a difference in the compellingness of role models might be important in discouraging some from developing complex intellectual abilities. Relatedly, I argued that, when opportunity is competitive, socialization requires that some competitors become discouraged and drop from the competition. Both points arise from the Rawlsian assumption that labor is divided into a few positions requiring highly trained abilities and many more positions that require less skill. Perhaps this division of labor blunts the development of intellectual potential in children. If the sociology on which Rawls bases the assumed division of labor is itself flawed, then we have reason to seek another way of understanding social justice.

Rawls's assumption that labor must be organized so that many do simple labor while a few others do more complex labor is rooted in his belief that the difference principle has an application, that some inequalities benefit everyone. Discussing, in Restatement, whether all the basic liberties should be guaranteed their fair value, Rawls writes, 'If that guarantee means that income and wealth are to be distributed equally, it is irrational; it does not allow society to meet the requirements of social organization and efficiency' (151). These remarks recall the discussion of efficiency, the difference principle, and perfect justice at Theory 68-9; there he writes that a perfectly just scheme is one where the expectations of the least advantaged group are as high as the expectations of the least advantaged group in any alternative scheme. When the difference principle is 'fully satisfied' (when perfect justice is achieved), it is 'impossible to make any one representative man better 
off without making another worse off.' In that sense 'a perfectly just scheme is also efficient' (69). At Restatement 151 he seems to be assuming that, if wealth and income were equal, then we all would be worse off than the least advantaged would be if we allowed some inequality. Why? Because we would be debarred from using incentives that would motivate the more talented and raise the levels of income and wealth for all of us.

Hence the requirement of efficiency seems to be the source of Rawls's belief that deep inequalities are inevitable. Here I sketch the sociological assumptions implicit in the belief that perfect justice requires profound inequality. The first two assumptions could together be called 'the meritocrat's dream.'

1. Rawls believes that efficiency requires that social positions be organized so that some require scarce developed abilities while others require only more easily acquired abilities (for example, we need more construction workers than architects); that is, there is a division between complex and simple labor. ${ }^{13}$

2. He assumes (I will argue) that the distribution of native potential at least roughly approximates the distribution of positions requiring greater or less training and highly developed skill in modern societies (as described in 1).

3. He assumes that at least some people with relatively scarce developed abilities needed for efficient production will contribute their abilities only given an extra incentive - additional income, wealth, or power; this is the assumption that inequalities allowed by the difference principle really do benefit everyone.

In this section we will examine these assumptions (and I will refer to them often by their numbers). On the third assumption: With G.A. Cohen we may ask why people require an extra reward to contribute their abilities. ${ }^{14}$ Would an equal share of the common benefit be insufficient incentive? And (Cohen's more specific question) could some-

13 See note 9 above and the appendix below for problems with attributing this assumption to Rawls.

14 If You're an Egalitarian, How Come You're So Rich? (Cambridge: Harvard University Press 2000), Chs. 8 and 9 as well as other essays cited there. These challenges are further developed in Rescuing Justice and Equality (Cambridge, MA: Harvard University Press 2008), which I have not yet read. 
one endorse the difference principle and still bargain for recompense greater than others'? Later I propose an idea nearly the opposite of the third assumption.

However, I will focus my discussion on the meritocrat's dream. For reasons to be explained Rawls needs assumption 2, which is almost surely false. Moreover, 1 is a much more profound source of unequal opportunity than 3 . So if 2 is false and the division of labor assumed in 1 is unnecessary, we have reason to look at justice in a different way.

\section{The meritocrat's dream}

Suppose an efficient society divides social positions into those requiring greater and lesser complex knowledge and skill; giving all children fully nurturing environments, some develop ability to fulfill duties of positions requiring greater complexity, and others never do. ${ }^{15}$ In those equally and fully nurturing environments, the number of people who develop complex abilities is roughly equal to the number of positions needing complex abilities. Thus the structure of positions of an efficient society mirrors the abilities people develop in these nurturing environments. The society is efficient because it matches positions to people's native endowments and their development; social organization optimizes production so that all benefit. This is the meritocrat's dream. Is it true? ${ }^{16}$

Surely it is widely believed that there is a 'natural lottery' of ability, but what is meant by 'ability'? Talk of abilities is well defined when it concerns specific abilities and disabilities, such as color vision and deficits in it or 20/20 vision and myopia. We can investigate whether $20 / 20$ vision is affected by environmental or genetic variations. There may well be a natural lottery influencing who is myopic.

Although it may be widely believed that people are naturally suited to what they do, that they have natural gifts for philosophy, mathematics, or basketball, the belief may be neither well-grounded nor even meaningful. Talk of natural abilities often simply redescribes observed differences in what we can do as 'natural': some do philosophy very

15 I believe that this asks us to imagine what is socially impossible, that with equal opportunity everyone would be socialized for positions that only a few would attain.

16 The meritocrat's dream seems based on the functional theory of stratification, which was in the air when Rawls started graduate school. For discussion and references see my How to Make Opportunity Equal: Race and Contributive Justice (Malden, MA: Blackwell Publishing 2007), Ch. 9. 
well; others have great musical ability; this must be because some have a natural talent for philosophy, others for music. ${ }^{17} \mathrm{I}$ doubt that it is meaningful to speak globally of 'ability.' IQ psychology can give content to the idea of global ability but cannot rescue that idea. The IQ test is not a measuring instrument comparable to an ammeter or a mass spectrometer, embedded within relatively uncontroversial theory. It has a dubious history of connection to theories of class and racial inferiority. ${ }^{18}$

It would be remarkable if there were a lottery of human potential corresponding to the organization of social positions into a few requiring mastery of very complex abilities and most requiring more rudimentary skills. For tens of thousands of years, perhaps over a hundred thousand, anatomically and culturally modern humans flourished and spread over the earth in societies with limited division of labor, primarily by age and gender. Judging from recent peoples who have lived in groups with rudimentary division of labor, we may infer that social, cultural, and subsistence activities required exercise of complex thought and detailed knowledge of one's environment. ${ }^{19}$ It takes great social skill to maintain harmony, to cooperate, and to resolve differences absent a state that centralizes force. ${ }^{20}$ Mastery of complex abilities is spread widely among group members. Modern humans evolved in such egalitarian groups. Less than ten thousand years ago, class structure arises, divisions between rulers and ruled, some planning production and others carrying out labor tasks under instruction and supervision. ${ }^{21}$

17 For criticism of these ideas see How to Make Opportunity Equal, Chapter 10, where I argue that the 'because' here is not an explanation.

18 Leon Kamin, The Science and Politics of IQ (Potomac, MD: Lawrence Erlbaum Associates 1974), especially Chapter 1 and my How to Make Opportunity Equal, Chapter 10. On related issues see Brian Barry, Why Social Justice Matters (Cambridge: Polity Press 2005), Chapters 8 and 9; there is much else.

19 On nomadic foragers there is much; see, for example, Richard Lee, The Kung San: Men, Women, and Work in a Foraging Society (Cambridge: Cambridge University Press 1979); the essays in Eleanor Leacock and Richard Lee, eds., Politics and History in Band Societies (Cambridge: Cambridge University Press 1982); Colin Turnbull, The Forest People: A Study of the Pygmies of the Congo (New York: Touchstone 1961); Jean L. Briggs, Never in Anger: Portrait of an Eskimo Family (Cambridge, MA: Harvard University Press 1970).

20 On the hypothesis that the intelligence of modern humans arises to master social complexity and negotiate a complex social terrain see Robin Dunbar, Grooming, Gossip, and the Evolution of Language (Cambridge, MA: Harvard University Press 1996).

21 On the rise of state-level societies and some of the differences it makes for social organization see Jonathan Haas, The Evolution of the Prehistoric State (New York: Columbia University Press 1982); Morton Fried, The Evolution of Political Society: 
Labor under close supervision becomes routine, even mindless. (Adam Smith notes the negative effect of such labor on the worker's mind and contrasts the dullness of laborers with the intelligence of people living in 'barbarous societies.') $)^{22}$ Specialists develop writing, record keeping, and systematic knowledge of the heavens. Children from different social classes are socialized for different adult positions. Of course, it was widely believed, as Aristotle evidences, that some were born to rule and others to serve. But it would be remarkable if it were true, given the evolution of human society. If we interpret Rawls's belief in a lottery of 'native endowments' as an approximation of the meritocrat's dream, then it is a contemporary version of Aristotle's belief, and it is almost surely false.

Not even Rawls believes fully in the meritocrat's dream. In both Theory and Restatement Rawls considers the objection that differences required as incentives will create large economic inequalities. In Restatement he replies that 'given the basic liberties and fair equality of opportunity, the open competition between the greater numbers of the well-trained and better educated' will prevent great income inequalities (67; cf. Theory 136-7, 270). This reply seems to assume that the number of people trained and educated will exceed the number of positions requiring such training and education.

By how much? If the number trained and capable greatly exceeds the number of positions requiring such training, if most normal people can fill those positions, then the society with only a few positions of advantage is irrational or unjust. Capable physicians work as phlebotomists because only a few physicians are needed even though many more are capable of being physicians and, with equal opportunity, have so trained themselves. This is irrational. Or, if most children have the potential to be physicians or managers but only a few are needed, then society might train only a very few more than are needed. But if this is the case, then the resulting society blunts the development of children's intelligence so that their developed abilities match what they will do. It is unjust to discourage children from developing abilities. To avoid these objections Rawls could assume that the number with greater 'native ability' only slightly exceeds the number of positions requiring it. I have

An Essay in Political Anthropology (New York: McGraw-Hill 1967); Allan Johnson and Timothy Earle, The Evolution of Human Societies: From Foraging Group to Agrarian State (Stanford: Stanford University Press 1987; and my 'How Morality Works and Why It Fails: On Political Philosophy and Moral Consensus,' The Journal of Social Philosophy 28 (1997) 43-70.

22 An Inquiry into the Nature and Causes of the Wealth of Nations (Chicago: University of Chicago Press 1976), Volume 2, 302-5 (Book V, Chapter I, Part III, Article II). 
no idea why anyone would believe this. We should regard assumption 2 as implausible at best (at worst, the idea of ability is undefined).

If Rawls's conception of equal opportunity is to make sense, he needs the assumptions comprising the meritocrat's dream. If, as is likely, potential to master complexity is nearly universal in human populations, then it is unjust to bring children up in such a way as to blunt their development of that potential. If we reject 2, Rawls's view of equal opportunity is implausible. Social organization should not make it impossible for many children to develop and, as adults, to contribute complex abilities.

\section{Effects of the division of labor on equal opportunity: \\ Rawls's assumption 1}

If there is no natural lottery suiting people for positions created by the division of simple from complex labor, what are we to say about that division itself? This division is incompatible with truly equal opportunity for a quite general reason suggested earlier. Because children are socialized to the positions they hold as adults (the socialization principle), then some children will be socialized for routine labor and a much smaller number for positions requiring more developed abilities. ${ }^{23}$ These differences in socialization are familiar from all class societies. It may work through parental socialization where differences in the cultural attainments of parents - attainments reinforced in day-to-day work life - are conveyed to children as competitive advantages and disadvantages. Or it may work in other ways. But those who grow up with fewer advantages will - for that reason alone - do more simple routine labor, and this is unfair. If we seek to develop abilities in all children, we must abolish this division of labor.

\section{Contributive Justice as an Alternative to Rawlsian Opportunity}

A lot rests on whether there is a natural lottery corresponding to the assumed division of labor. If, as I think plausible, the potential to master complexity is widespread in human populations, then socialization for routine labor requires blunting the development of human abilities in many children. This is unjust. This injustice has been acknowledged

23 See How to Make Opportunity Equal, Chapter 3 for a detailed discussion of the socialization principle. 
when it was specifically racial — when black children were targeted for 'vocational education.' We now need to recognize the injustice more broadly. Justice to children requires that they be encouraged to develop their potential.

My belief that it is unjust to inhibit children's development of their abilities is grounded in the following thoughts: where social structures unnecessarily impede or prohibit people from leading a good life, the society in question is defective; where they impede some to the advantage of others, when this is unnecessary, the society is unjust. Then to sustain the claim that Rawls's imagined well-ordered society is unjust (because it impedes the development of ability in children from some social classes) I need to show how something better is possible.

My suggestion is that labor be shared, specifically whatever routine, relatively mindless labor is necessary to provide us with goods and services; all must do it. This sharing would eliminate the differences, grounded in the socialization principle, in the ways children are socialized, some for lives of simple labor, others for lives of complex labor. Because no one's life would be consumed by simple labor, sharing labor would provide everyone with opportunity to develop complex abilities, to contribute those abilities to society, and to earn esteem for contributions of complex labor, provided that complex labor too is shared among all who demonstrate the relevant mastery. The development and contribution of our abilities and the earning of esteem for contributions are human goods. ${ }^{24} \mathrm{~A}$ just society should make available to all the opportunity to attain these goods. A conception of contributive justice articulates the central norms that would make these goods available to all simultaneously and non-competitively. ${ }^{25}$

In the section on the idea of a social union Rawls defends one division of labor. While his discussion is rather abstract, what he has in mind, I think, is that it is inevitable that we will not develop all of our potential to master complexity: I had the potential, let us suppose, to be an architect, a surgeon, a musician, a lawyer, and a philosopher. But it is impossible to be all of these. So I contribute as a philosopher, while I enjoy listening to the music of others and benefit from others' surgical abilities, architectural achievements, and so forth. Thus the development of our abilities is complementary (Theory 464). I agree with Rawls that the complementary development of different complex abilities in different people is inevitable in a modern society. 
What is not necessary is that some are socialized for routine, simple, unskilled labor, while others are encouraged to develop more complex mastery and have the opportunity to contribute that mastery and earn esteem for that contribution. Comparing the two types of labor leads to contempt for the contributions of those whose labor is simpler. If everyone does a share of routine labor, it ceases to be a ground for social contempt. Moreover, while it cannot be guaranteed that everyone will win esteem for contribution of complex mastery (some may fail to master any complex ability or may refuse to contribute their complex mastery to the group), the social barriers to everyone's winning esteem simultaneously for their contributions will have been removed. Moreover, for reasons that Rawls's discussion of complementary labor makes clear and because larger communities of people sharing an ability enhances everyone's ability (as in a larger community of good philosophers each makes others better), we have reason to encourage others in their development and contribution of their abilities. ${ }^{26}$

I argued earlier that, for the most part, Rawls believes that the important opportunities are for goods that are received. Rawls is concerned with distributive justice more than justice as it concerns our labor. One exception is the passage at Theory 73, which implies that 'a skillful and devoted exercise of social duties' is an important good for which we ought to have opportunity. Contributive justice is built around that idea. We are then rejecting the difference principle: more skilled and challenging positions do not require an extra extrinsic incentive because they are already intrinsically more desirable. Developing and contributing those abilities is a good that, other things being equal, most prefer to routine labor. Our conception of justice is contributive rather than distributive. That is, the most important goods are our contributions to a social group. Justice makes contributive goods available to all simultaneously. Unlike material goods that are distributed, contributive opportunities might be of unlimited supply if we share labor so that all children can develop their abilities to the fullest and, as adults, contribute developed abilities to society. This is a very different conception of justice from Rawls's, but it is a conception of justice that would allow truly equal opportunity. ${ }^{27}$

26 See How to Make Opportunity Equal, Chapter 8 for further explanation of how sharing labor makes it possible to have nurturing rather than competitive relations with others.

27 But see the appendix for a discussion of whether Rawlsian justice could accommodate contributive justice. 


\section{Conclusion}

Rawls believed that the effect that class of origin inevitably had on children's life prospects was compatible with 'fair equality of opportunity.' I have shown how Rawls's conception of equal opportunity is embedded in his sociology. We cannot achieve truly equal opportunity within the framework of his sociological assumptions. So Rawls was right, given his sociology, to conceive of equal opportunity as he did.

Nevertheless, many of us - or at least I - find unsatisfactory a conception of justice that allows that children from disadvantaged groups are less likely to develop abilities and, as adults, contribute these to society. Among other things, this represents too weak a rejection of racial disadvantage as a special case of class disadvantage. We should seek a conception of justice that allows all children to develop and contribute whatever abilities they may be capable of developing. But given the socialization principle - that children will be socialized for available opportunities and, where desirable opportunities are limited, many will be socialized for inferior options - we would need to reject the organization of labor that leads to limited opportunity. Instead of thinking of the important opportunities as ones to receive material goods (thus Rawls's conception of efficiency as efficiency in the production of commodities), we should regard the most important opportunities as opportunities to contribute our abilities to society. If these opportunities are unlimited, then the socialization principle would allow that a just society could develop the abilities of all children. Contributive opportunities could be unlimited if all labor - both routine and complex - is shared among all with the relevant abilities. The central norms of a contributive conception of justice would ensure that these contributive opportunities are available to all equally.

Received: February 2008

Revised: December 2008 


\section{APPENDIX: ARE THERE TWO EGALITARIANISMS IN RAWLS?}

This appendix is essentially a long footnote addressing what seem to be two irreconcilable egalitarian views in Rawls's thought. The question mark in the title is because $I$ do not see how to resolve these apparent conflicts. Perhaps others can.

The present paper is a critique of what I will call the dominant strain in Rawls's egalitarianism. In that strain there are inevitably 'profound inequalities' in people's life prospects; the inequalities arise from the demands of efficiency (which lead to the difference principle); efficiency requires a division of labor between more and less skilled positions and differences in material rewards to the more demanding positions requiring extensive training of scarce native potential. These profound inequalities in both material resources (Rawls's apparent emphasis) and in the esteem earned by social contributions (emphasized in the present paper) are grounded in the effects of the natural and social lotteries, as well as luck and other contingencies, and the requirements of efficiency. The inequalities are serious enough that the less advantaged are inclined to envy the more advantaged, a problem which Rawls addresses in $\$ \S 80$ and 81 of Theory. ${ }^{28}$ The resulting inequalities are just because they increase production and hence the goods available to those least advantaged. The emphasis here is on distributive justice and maximizing the distributive share of the least well off group.

There is another strain in Rawls's egalitarianism. In that secondary strain contribution is a central good, and we find self-realization through skilled performance of social duties. A property owning democracy leads to a wide dispersal of property and of the powers entailed by ownership. There is workplace democracy. ${ }^{29}$ The 'worst aspects' of the

28 The problems created by inequality even within a Rawlsian well ordered society are quite serious; Rawls imagines they are lessened by the fact that less advantaged and more advantaged form non-comparing social groups so that (my examples) janitors compare their material resources and social esteem with janitors and cabdrivers while architects compare themselves with architects and engineers. He seems to find the inequalities between the groups severe enough that these separate associations are helpful in diminishing 'the number of occasions when the less favored are likely to experience their situation as impoverished and humiliating.' I find this appalling; one of his proposed solutions - separation into non-comparing groups - seems to represent a recognition that, on his view of justice, there is no common basis for social esteem that allows all to be esteemed.

29 Samuel Freeman's Rawls (London: Routledge 2007), 113 emphasizes these and generally develops the secondary strain into an interpretation of Rawls. I do not understand how Freeman takes account of the dominant strain. 
division of labor are overcome; 'no one need be servilely dependent on others and made to choose between monotonous and routine occupations which are deadening to human thought and sensibility. Each can be offered a variety of tasks so that the different elements of his nature find a suitable expression.' '[W]ork is meaningful for all' (Theory 464). (This is followed by a discussion of how labor specialization is complementary, as discussed earlier.) Throughout this section (\$79 The Idea of Social Union) I find no hint of inequality or of beneficiaries and losers in the natural lottery. Rather we bring different (not unequal) abilities to one another and cooperate on that basis.

A natural lottery of ability also seems absent at Theory $\$ 47$ at 268-69 where he considers a 'perfectly competitive economy surrounded by a just basic structure.' Under these circumstances 'the relative attractiveness of different jobs will be equal, all things considered.' Jobs that would be otherwise less desirable will be better paid. But note that in the situation Rawls imagines, inequalities in life prospects created by the basic structure have disappeared. Moreover, the difference principle is not doing any work since there are no social or economic inequalities. $^{30}$

Here I note these two strains but do not reconcile them. Perhaps they cannot be reconciled; in work as groundbreaking as Rawls's it should not be surprising that there should be unresolved problems or that the view could be developed in contradictory ways - particularly if Rawls was unclear in his own sociological assumptions.

Could Rawlsian thought be developed to include what I have called contributive justice? The social bases of self-respect could be thought to include the esteem we earn for our social contributions. Because complex labor earns more esteem, the difference principle might require that the labor be organized so as to maximize the opportunities of the least advantaged group to contribute complex abilities. This would lead, within a Rawlsian framework, to breaking down the division between simple and complex labor.

The previous paragraph puts the argument of this paper in Rawlsian language. But Rawls never developed his thought in this way and it seems incompatible with how he imagines the application of the difference principle. Moreover, his conception of justice addresses

30 My attention to this passage was drawn by Richard Krouse and Michael McPherson's 'Capitalism, "Property-Owning Democracy," and the Welfare State' in Amy Gutmann, ed., Democracy and the Welfare State (Princeton: Princeton University Press 1988). Rawls cites this essay favorably in Restatement at $135 \mathrm{n} .2$ and repeats some of its argument (without citing it) in the preface to the revised edition of Theory at xiv-xvi. 
primary goods that are in scarce supply (the circumstances of justice) while sharing labor would make unlimited the opportunity to develop and contribute our abilities. Equally important, Rawls is committed to market mechanisms and to property owning democracy, and - I have argued this elsewhere - market norms are not compatible with contributive justice. $^{31}$

In Rawls's thought there are two rival views of the good. The dominant view is Kantian: we have higher order interests in the development of our two moral powers (a sense of justice and a conception of the good) and in advancing the conception of the good we have formed. ${ }^{32}$ Efficiency requires inequality in order to maximize the income and wealth available to the least advantaged to advance their conception of the good. The result is deep inequalities. The other view of the good is Aristotelian with a Marxist influence. The good is human activity, and the best societies are ones that enable universal flourishing through self-realizing activity, particularly social labor. Through cooperative labor that develops the abilities of each, each person earns esteem from self and others. This second view of the good is the ground of contributive justice, but I cannot reconcile it with the dominant strain in Rawls's thought. $^{33}$

31 How to Make Opportunity Equal Chapters 12 and 13.

32 Explained in 'Kantian Constructivism in Moral Theory,' in Collected Papers, especially 312-13.

33 My thinking about these issues was originally influenced by conversations with Anthony Laden and Daniel Brudney. Early drafts of this paper were a chapter of the manuscript that became How to Make Opportunity Equal, but the chapter was excised from the final version of the book to make the book more accessible to a wider audience. The chapter drafts were criticized by Laden and G.A. Cohen, and this led to a great improvement. A section of the paper was the topic of an APA colloquium where it received some criticism from Charles Mills. Mahesh Ananth read a draft and offered encouragement in pursuing the argument. I received searching criticism of a draft from an editor and two referees for CJP; these led to a substantial rewrite and, I think, major improvement. Finally David Copp and Laden reassured me that the appendix was not insane. I thank all of you. 
Copyright of Canadian Journal of Philosophy is the property of University of Calgary Press and its content may not be copied or emailed to multiple sites or posted to a listserv without the copyright holder's express written permission. However, users may print, download, or email articles for individual use. 